\title{
Test Verification and Application of a Longitudinal Temperature Force Testing Method for Long Seamless Rails Using FBG Strain Sensor
}

\author{
Ping Wang, ${ }^{1}$ Kaize Xie, ${ }^{1}$ Rong Chen, ${ }^{1}$ Liyang Shao, ${ }^{2}$ Lianshan Yan, \\ Hao Liu, ${ }^{1}$ and Meng Zhang ${ }^{2}$ \\ ${ }^{1}$ MOE Key Laboratory of High-Speed Railway Engineering, Southwest Jiaotong University, Chengdu 610031, China \\ ${ }^{2}$ School of Information Science and Technology, Southwest Jiaotong University, Chengdu 610031, China
}

Correspondence should be addressed to Rong Chen; chenrong@home.swjtu.edu.cn and Liyang Shao; lyshao@home.swjtu.edu.cn

Received 25 March 2016; Accepted 24 May 2016

Academic Editor: Zhenhua Zhu

Copyright (c) 2016 Ping Wang et al. This is an open access article distributed under the Creative Commons Attribution License, which permits unrestricted use, distribution, and reproduction in any medium, provided the original work is properly cited.

In order to evaluate the health status of continuous welded rail accurately, a deduction on the FBG sensing principle has been made with regard to the temperature variation of test specimens under different constraint conditions. A long seamless rail testing solution and its on-site application are designed based on this deduction. According to the verification experiments of sensing principle inside, the effect of the reference temperature on the FBG temperature and strain sensitivity coefficient within $-30^{\circ} \mathrm{C} \sim 30^{\circ} \mathrm{C}$ is not higher than $0.05 \%$; the maximum relative error of single point between the tested and theoretical results of test specimen under constrained condition is 3.2\%; and the maximum relative error of slopes of fitted straight lines based on the tested and theoretical results within the entire test temperature range is $2.3 \%$, verifying the deduced FBG sensing principle with regard to the test specimen under constrained condition. The maximum error of the longitudinal temperature force between the on-site tested results and calculated results in long seamless rails is only $6.1 \mathrm{kN}$, the corresponding rail temperature variation is $0.3^{\circ} \mathrm{C}$, and the accumulated error is controllable within $5 \%$.

\section{Introduction}

Continuous welded rail (CWR) is an important symbol of railroad track modernization and has been developed widely in the world because of its advantages such as higher traveling stability, longer rail service life, noise and vibration reduction, low maintenance load, and energy consumption [1-3]. At present, the total length of CWR in the world has reached up to $500,000 \mathrm{~km}$, accounting for $1 / 3$ of the total mileage of railway lines. Accurately obtaining real-time quality information about CWR and ensuring its excellent service have become a new technical problem for the international railway industry, and the dynamic variation of longitudinal temperature force aggregated inside long seamless rails is the key issue $[4,5]$. Since the 1930s, many researchers have been developing many techniques to try measuring the longitudinal temperature force of rails [6-11]. The resistance strain gauge, applied early and developed maturely, has been widely used as a strain method for testing the longitudinal temperature force in long seamless rails $[12,13]$. However, it is liable to be affected by the complicated railway transportation environment and therefore cannot satisfy the requirements of long-term service. The introduction of Fiber Bragg Grating (FBG) provides a new approach for testing the longitudinal temperature force in long seamless rails for researchers.

Since Morey et al. researched the fiber grating strain and temperature sensor for the first time in 1989 [14], many researchers were attracted to performed wide application research considering its dominance such as independence from electromagnetic interference and light intensity fluctuation of light paths, as well as its advantages of specific wavelength coding and distributed sensing. The fiber grating technology has been developed rapidly within just over 20 years in the sensing field and applied successfully in many fields such as aerospace, civil engineering, composite materials, and the petrochemical industry [15-20]. At present, fiber 
grating has also met great success in railway construction; however its application is mainly limited to dynamic traintrack interaction measurements [21]. For example, Wei et al. established an axle counting system with FBG sensors based on the theoretical analysis of the effect of trains on rail deformation and gave creditability validation of the system through on-site tests $[22,23]$. Lai et al, with reference to the fast response of optical systems, established a system for monitoring the real-time vehicle operation through FBG sensors. This system can be used to quickly detect faults such as wheel defects and the offset load of trains [24]. Roveri et al. also used the same principle to design a FBG sensor array system for the real monitoring of railway track and train wheel which could estimate the wear of rail and wheel, key traffic parameters, and so on [25]. Buggy et al. monitored the strain of railway track components with arrays of FBG sensors during trains passing through to identify the features of the components [26]. Lee et al. researched the dynamic wheel-track interaction using FBG sensors for monitoring traveling trains to evaluate the possibility of derailment and performed relevant on-site tests successfully [27]. Schröder et al. presented an approach which could monitor the contact force between the catenary and current collector by FBG sensors $[28,29]$. Catalano et al. proposed an intrusion detection system made up of FBG sensors to protect the rail-tracks from physical barriers [30]. Chapeleau et al. applied the FBG sensors during the fatigue test of ballastless track structure and the results show that cracks can be detected and localized by FBG sensors [31]. Many researchers in the world have also made deep studies in testing the longitudinal force of rails with FBG sensors. For example, Yoon et al., with the Brillouin optical correlation domain analysis, tested the longitudinal strain of rails under a certain vertical dynamic load. The testing accuracy can reach up to $\pm 15 \mu \varepsilon$ [32]. Wang et al. measured the additional contractility caused by the track-bridge interaction and its distribution of CWR on viaducts with FBG sensors [33]. However, since the additional contractility was always affected by factors such as resistance of track and temperature variation of bridge and rail, the true value was hard to obtain, and therefore no corresponding contrast was made in the test. These studies are unable to solve the problem of testing the longitudinal temperature force in long seamless rails effectively and no effort based on the sensing of FBG has been made to verify the scientific basis and effectiveness of testing longitudinal rail temperature force using FBG strain sensors in existing studies. Therefore the reasonableness of the tested results is still in dispute.

Hence, in this paper, with reference to the temperaturestrain cross sensitivity of the fiber grating, the FBG sensing principle of the test specimen under different constraint conditions is obtained by theoretical derivation and verified through indoor tests. Thus the effectiveness of FBG for testing the longitudinal temperature force in long rails is also proven. Then, based on the FBG sensing principle of the test specimen under different constraint conditions, the long seamless rail testing solution and its on-site application are designed. The test is a success. This paper aims to ascertain the principle of using FBG sensors to test the longitudinal temperature force in rails and lay a stable foundation for further application of FBG in railway construction.

\section{FBG Sensing Principle in Testing Longitudinal Temperature Force of Rails}

The long seamless rails of railway lines cannot contract or expand freely along the direction of the line when temperature changes due to the constraint of fasteners, and therefore a certain degree of longitudinal force can be generated in them, which is called the longitudinal temperature force of long seamless rails. In the vertical direction, only part of the rail bottom is supported by the substructure; the free deformation of rail section is allowed when the temperature changes; see Figure 1. The FBG sensing principle with regard to the specimens tested under free or constrained conditions simulating the two different above-mentioned constraint states of long seamless rails can be deduced.

2.1. Sensing Principle of Fiber Grating. Fiber grating means the singularity generated by the projection spectrum and reflection spectrum causing a special wavelength to undergo mode coupling that is caused by the change of fiber wave guide conditions in consequence of the periodic change of the core refractive index. According to the mode-coupling theory, the central wavelength of reflection spectrum of the fiber grating is [34]

$$
\lambda=2 n_{\mathrm{eff}} \Lambda,
$$

where $\lambda$ refers to the central wavelength of the fiber grating, $n_{\text {eff }}$ refers to the effective refractive index of the core, and $\Lambda$ refers to the fiber grating period. Therefore all factors affecting the fiber grating period and effective refractive index will cause a shift of central wavelength of the fiber grating. The most direct affecting factors are strain and temperature, and the relative central wavelength shift of the fiber grating caused by them is

$$
\frac{\Delta \lambda}{\lambda}=K_{\varepsilon} \Delta \varepsilon+K_{T} \Delta T
$$

where $\Delta \lambda$ refers to the variation of the central wavelength relative to reference point of the central wavelength $\lambda ; K_{\varepsilon}$ and $K_{T}$ refer to the strain and temperature sensitivity coefficients of the fiber grating, respectively. The temperature sensitivity coefficient of the fiber grating is mainly determined by the thermooptic coefficient $\zeta$ of the fiber grating and the thermal expansion coefficient $\alpha$ of the optical cable; that is, $K_{T}=\zeta+\alpha$. $\Delta T$ refers to the temperature variation of the fiber grating. $\Delta \varepsilon$ refers to the axial strain variation caused by a defined external force. Formula (2) also expresses the temperature-strain cross sensitivity of the fiber grating.

2.2. Unconstrained Test Specimen. When the direction of the specimen to be tested is unconstrained, the FBG sensing principle is the same as that of its temperature sensitization encapsulation; see Figure 2. 


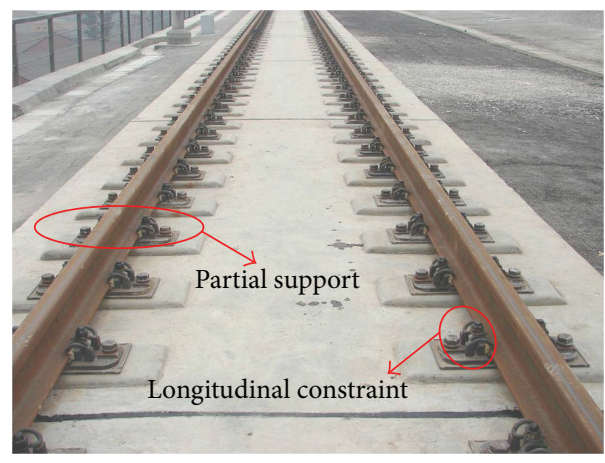

FIGURE 1: Constraint conditions of CWR.

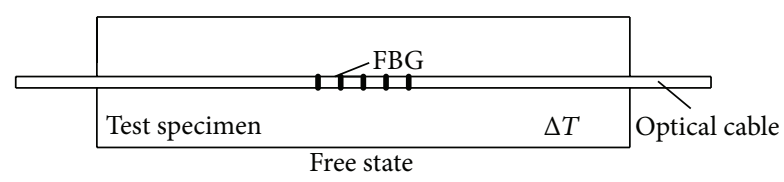

FIGURE 2: Unconstrained test specimen.

When the temperature of the test specimen changes as $\Delta T$, for FBG,

$$
\begin{aligned}
\varepsilon & =\left(\alpha_{s}-\alpha\right) \Delta T, \\
\frac{d \Lambda}{\Lambda} & =\alpha_{s} \Delta T .
\end{aligned}
$$

According to theories of photoelastic effect, waveguide effect, and thermooptic effect, differential form of the effective refractive index is

$$
d n_{\mathrm{eff}}=\frac{\partial n_{\mathrm{eff}}}{\partial L} \Delta L+\frac{\partial n_{\mathrm{eff}}}{\partial a} \Delta a+\frac{\partial n_{\mathrm{eff}}}{\partial T} \Delta T .
$$

The waveguide effect has little impact on the sensitivity coefficients of fiber grating, so the second item of Formula (3c) can be ignored. Then Formula (3c) can be written as

$$
\begin{aligned}
\frac{d n_{\mathrm{eff}}}{n_{\mathrm{eff}}} & =\frac{1}{n_{\mathrm{eff}}}\left(\frac{\partial n_{\mathrm{eff}}}{\partial L} \Delta L+\frac{\partial n_{\mathrm{eff}}}{\partial T} \Delta T\right)=-P_{e} \varepsilon+\zeta \Delta T \\
& =-P_{e}\left(\alpha_{s}-\alpha\right) \Delta T+\zeta \Delta T,
\end{aligned}
$$

where $\alpha_{s}$ refers to the thermal expansion coefficient of the test specimen, for metallic materials, $\alpha_{s}>\alpha$; $P_{e}$ refers to the effective elastooptical coefficient; $\Delta L$ and $\Delta a$ refer to the change of longitudinal length and diameter of the optical cable, respectively. Substitute Formulas (3a), (3b), (3c), and (3d) into the total differential equation of the fiber grating resonance equation and suppose that the FBG strain sensitivity coefficient is expressed as $K_{\varepsilon}=1-P_{e}$; then the FBG sensing principle under this state can be obtained as

$$
\begin{aligned}
\frac{\Delta \lambda}{\lambda} & =K_{\varepsilon}\left(\alpha_{s}-\alpha\right) \Delta T+(\zeta+\alpha) \Delta T \\
& =\left[K_{\varepsilon}\left(\alpha_{s}-\alpha\right)+K_{T}\right] \Delta T .
\end{aligned}
$$

From Formula (4), since $\alpha_{s}>\alpha$, then $K_{\varepsilon}\left(\alpha_{s}-\alpha\right)>0$; thus the FBG temperature sensitivity coefficient can be enhanced.
2.3. Constrained Test Specimen. When the direction of the specimen to be tested is constrained, the test specimen can be considered as the superposition of the two conditions as shown in Figure 3 ( $a$ and $b$ ) based on the equivalent load and strain, where $E$ refers to Young's modulus of the test specimen. State (a) is the same as that of the unconstrained test specimen, and the relative variation of the corresponding central wavelength can be calculated with reference to Formula (4). For State (b), the fiber grating is used under an even axial strain and at this time the relative variation of the central wavelength is

$$
\frac{\Delta \lambda}{\lambda}=K_{\varepsilon} \varepsilon=-K_{\varepsilon} \alpha_{s} \Delta T
$$

The FBG sensing principle with regard to specimens tested under constraint conditions can be concluded based on States (a) and (b):

$$
\begin{aligned}
\frac{\Delta \lambda}{\lambda} & =\left[K_{\varepsilon}\left(\alpha_{s}-\alpha\right)+K_{T}\right] \Delta T-K_{\varepsilon} \alpha_{s} \Delta T \\
& =-K_{\varepsilon} \alpha \Delta T+K_{T} \Delta T .
\end{aligned}
$$

It can be seen from Formula (6) that the relative variation of the corresponding central FBG wavelength will be independent of the thermal expansion coefficient of the test specimen when the test direction of the specimen is constrained and the temperature changes, and the FBG will not emit its temperature strain but it will be reflected in the sensing principle in the form of compressive strain due to the constrained test specimen.

\section{Indoor Test}

In order to verify the correctness of the FBG sensing principle when the test specimen is constrained, an indoor test is designed. From Formula (6), it can be seen that the FBG temperature and strain sensitivity coefficients should be obtained first. Therefore a test plan covering how to obtain the FBG temperature and strain sensitivity coefficients involved in the sensing principle should be laid for the purpose of verifying Formula (6).

3.1. Test Plan. The test plan laid according to the experimental purpose is shown in the following.

Step 1. Put the FBG freely into a TCB (temperature control box), gradually adjust the temperature inside the TCB to change the temperature of the FBG, and test the central wavelength of the FBG when the temperature at each step stabilizes. The temperature sensitivity coefficient of the FBG can be obtained based on the tested results and Formula (2).

Step 2. Attach the FBG from Step 1 to the test specimen, place them freely into the TCB, gradually adjust the temperature inside the box to change the temperature of the test specimen, and test the central wavelength of the sensor after the temperature of the specimen stabilizes. The strain sensitivity coefficient of the FBG can be obtained based on the sensing principle of Formula (4) and the tested results of Step 1. 


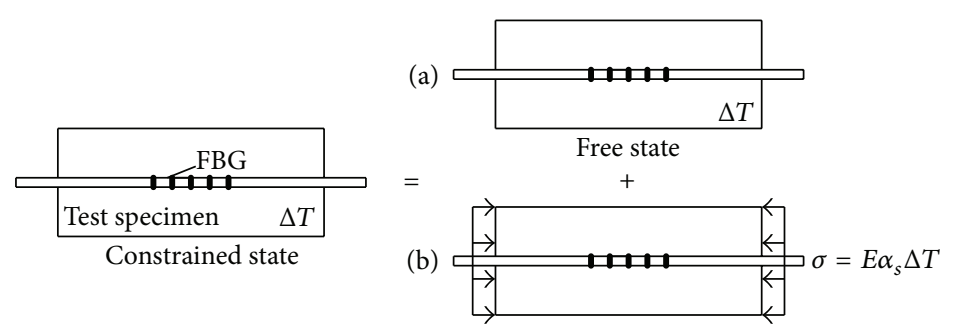

FIgURE 3: Constrained test specimen.

Step 3. Put the test specimen with FBG attached as mentioned in Step 2 on the loading platform of a universal testing machine and then put them into the TCB.

Step 4. Adjust the temperature inside the box to a low level (the controlled temperature during the test is $-30^{\circ} \mathrm{C}$ ). After the temperature of the test specimen stabilizes, adjust the universal testing machine to exert a low initial force on the specimen along the direction of FBG and then keep the displacement of the loading device unchangeable during the whole test.

Step 5. Adjust the temperature inside the box step by step, and after the temperature of the test specimen stabilizes, test the central wavelength corresponding to FBG and the corresponding pressure of the universal testing machine.

Perform a contrast verification for the theory and tested results according to the datum from Steps 3, 4, and 5 as well as the FBG temperature and sensitivity coefficients obtained from Steps 1 and 2 and Formulas (6) and (4).

3.2. Test Apparatus. Considering that the FBG is prone to distributed sensing, two FBGs with central wavelengths of $1551 \mathrm{~nm}$ (sensor_A) and $1563 \mathrm{~nm}$ (sensor_B) are connected in series on a piece of optical cable for the test. For common optical cables, the thermal expansion coefficient $\alpha$ is $(5.45 \pm$ $0.05) \times 10^{-7} /{ }^{\circ} \mathrm{C}$, while for the theoretical analysis, $5.5 \times$ $10^{-7} /{ }^{\circ} \mathrm{C}$ is used [34-37].

The test specimen is a size-reduced rail model. Young's modulus $E$, thermal expansion coefficient $\alpha_{s}$, and Poisson's ratio $\mu$ of the material are $2.1 \times 10^{11} \mathrm{~Pa}, 1.18 \times 10^{-5} /{ }^{\circ} \mathrm{C}$, and 0.3 , respectively. The sectional area $A_{s}$ of the rail model in the direction to be tested is $10.76 \times 10^{-4} \mathrm{~m}^{2}$.

The central wavelength of the FBG is tested with a single channel sm130 optical sensing interrogator. The testing accuracy is $1 \mathrm{pm}$. The allowed temperature variation range of the TCB used in the test is $-70^{\circ} \mathrm{C} \sim 180^{\circ} \mathrm{C}$. The temperature control accuracy is $\pm 0.5^{\circ} \mathrm{C}$. The temperature range selected in the test is $-30^{\circ} \mathrm{C}+30^{\circ} \mathrm{C}$. The variation at each step is $10^{\circ} \mathrm{C}$. The maximum range and accuracy of the universal testing machine in the test are $50 \mathrm{kN}$ and $0.1 \mathrm{~N}$, respectively.

3.3. Test Process and Results. The test is performed according to the above plan. Figure 4 shows the whole process of the indoor test and the relevant test apparatus.
Figure 5 shows the direct tested results from Step 1, where some time used to change the temperature is excluded in the abscissa. The range of temperature during the test is $-30^{\circ} \mathrm{C} \sim$ $+30^{\circ} \mathrm{C}$.

It is clear from the results shown in Figure 5 that the wavelengths of both sensors increase gradually as the temperature rises, and both the central wavelength variations of the two sensors corresponding to two consecutive temperature steps are about $8.8 \mathrm{pm}$, indicating that the central wavelength variation has a good linear relation with the temperature variation. After the temperature at each step stabilizes, the central wavelengths of the sensors will fluctuate slightly since they are constrained by the accuracy of the TCB and interrogator. The least square method can be adopted to treat the wavelength data at each temperature step and thus the errors caused by fluctuation of tested data can be greatly reduced, and at the same time further treatment of the data can be accomplished easily.

Figure 6, based on the data treatment shown in Figure 5, shows the relationship curve between the relative shift of the central wavelength (calculated when the central wavelength corresponding to the FBG is selected as the reference point under $-30^{\circ} \mathrm{C}$ ) and the temperature variation of sensors. From the fitting results, the relative shifts of both sensors used in the test have a strong linear relation with the temperature variation. All the coefficients of determination $\left(R^{2}\right)$ of fitted straight lines are higher than 0.998, and the slopes of the corresponding fitted straight lines are $5.626 \times 10^{-6}$ and 5.647 $\times 10^{-6}$, respectively. According to Formula (2), the slopes of the fitted straight lines under the conditions of Step 1 are the temperature sensitivity coefficient $K_{T}$ of the sensors. In addition, when results under different temperatures are selected as the reference points, the fitted straight slopes will differ to a certain extent; see Table 1.

It is clear from the results in Table 1 that all values of $R^{2}$ corresponding to the fitted straight lines with test results at different temperatures as reference points are higher than 0.998, indicating that their linearity is good. The slopes of the fitted straight lines differ to a certain extent; however the discrepancy is slight, with a relative variation less than $0.05 \%$, and therefore the effect of reference points on fitted slopes can be ignored in engineering applications. In order to standardize the indoor tests, the test result under $-30^{\circ} \mathrm{C}$ is selected as the reference point.

Figure 7 shows the direct tested result from Step 2. Figure 8, based on the process data shown in Figure 7, 


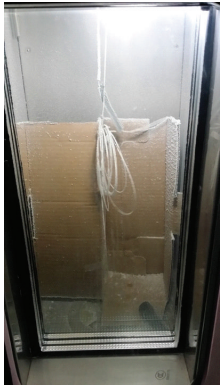

(a) Step $1\left(-30^{\circ} \mathrm{C}\right)$

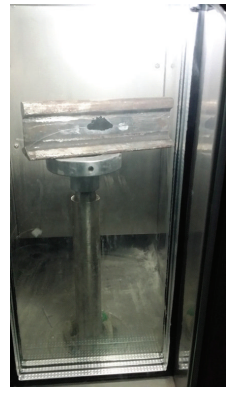

(b) Step $2\left(30^{\circ} \mathrm{C}\right)$

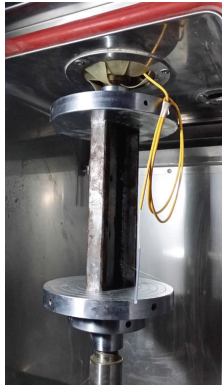

(c) Step $3 \sim 5\left(30^{\circ} \mathrm{C}\right)$

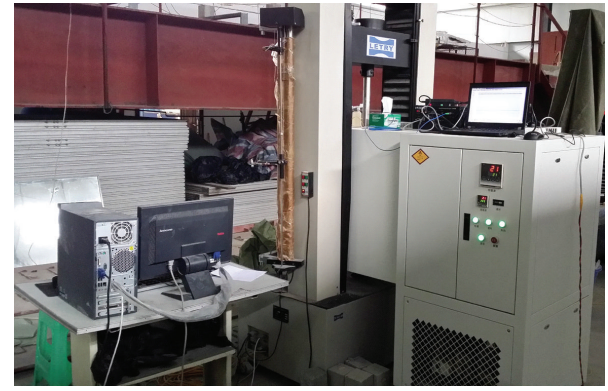

(d) Test apparatus

FIGURE 4: Test process and apparatus.

TABLE 1: Slopes of fitted straight lines corresponding to different reference points.

\begin{tabular}{lcccc}
\hline \multirow{2}{*}{ Ref. point temp. ${ }^{\circ}{ }^{\circ} \mathrm{C}$} & \multicolumn{2}{c}{ Sensor_A } & \multicolumn{2}{c}{ Sensor_B } \\
& $k_{\mathrm{A}}$ & $R^{2}$ & $k_{\mathrm{B}}$ & $R^{2}$ \\
\hline-30 & $5.626 \times 10^{-6}$ & 0.9986 & $5.647 \times 10^{-6}$ & 0.9983 \\
-20 & $5.625 \times 10^{-6}$ & 0.9986 & $5.647 \times 10^{-6}$ & 0.9983 \\
-10 & $5.625 \times 10^{-6}$ & 0.9986 & $5.647 \times 10^{-6}$ & 0.9983 \\
0 & $5.625 \times 10^{-6}$ & 0.9986 & $5.646 \times 10^{-6}$ & 0.9983 \\
10 & $5.624 \times 10^{-6}$ & 0.9986 & $5.646 \times 10^{-6}$ & 0.9983 \\
20 & $5.624 \times 10^{-6}$ & 0.9986 & $5.646 \times 10^{-6}$ & 0.9983 \\
30 & $5.624 \times 10^{-6}$ & 0.9986 & $5.645 \times 10^{-6}$ & 0.9983 \\
\hline
\end{tabular}

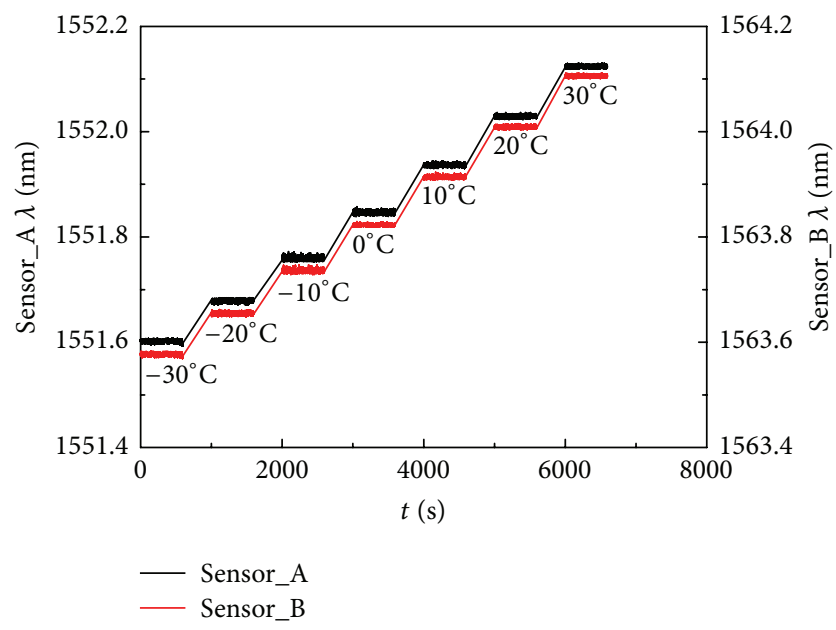

FIgURE 5: Tested result from Step 1.

shows the relationship between the relative shifts of the central wavelength (calculated when the central wavelength corresponding to the sensor is selected as the reference point under $-30^{\circ} \mathrm{C}$ ) and the temperature variation of the sensors.

In Figure 7, the wavelength variation is almost the same as that shown in Figure 5; however the fluctuation amplitude of wavelength corresponding to each step is lower compared with that shown in Figure 5, due to the fact that the FBG sensors are attached to the rail the volume of which is relatively large and the TCB accuracy has little effect on it. The central
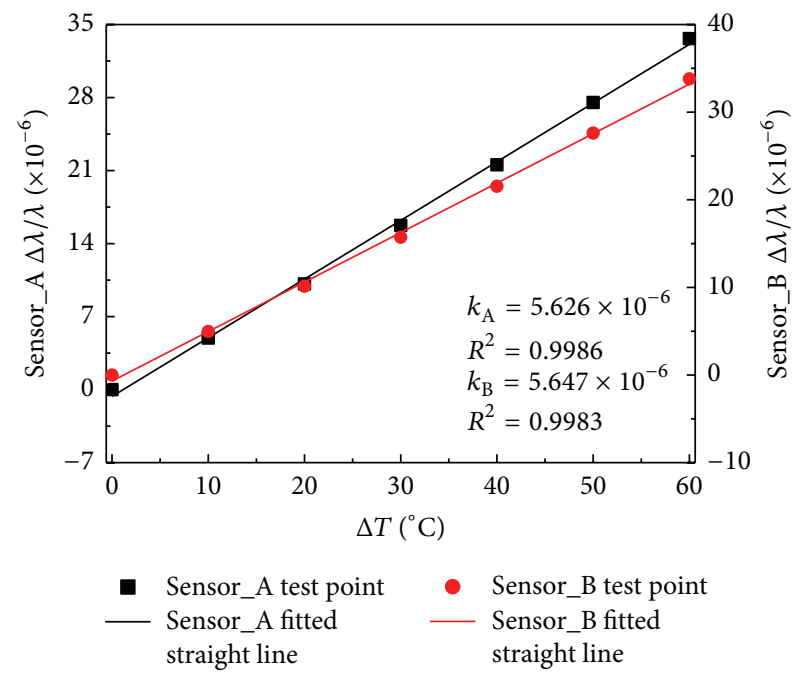

FIGURE 6: Fitting results.

wavelength variations of the two sensors corresponding to two consecutive temperature steps are $20.7 \mathrm{pm}$ and $22.3 \mathrm{pm}$, respectively, about 2.3-2.5 times that of the corresponding variation results shown in Figure 5. This is also the reason for achieving enhanced FBG temperature sensitivity through FBG-metal encapsulation.

From the fitting results shown in Figure 8, when two sensors are attached to a piece of unconstrained test rail, the linearity between the relative shift of the corresponding central wavelength and the temperature variation is better than that corresponding to the unconstrained bare grating. The slopes of fitted straight line corresponding to the two sensors are $1.338 \times 10^{-5}$ and $1.430 \times 10^{-5}$, respectively. According to Formula (4), the corresponding result of the slope is $K_{\varepsilon}\left(\alpha_{s}-\alpha\right)+K_{T}$.

The strain sensitivity coefficient of FBG can be obtained based on Formulas (2) and (4):

$$
K_{\varepsilon}=\frac{\left(k_{2}-k_{1}\right)}{\left(\alpha_{s}-\alpha\right)},
$$

where $k_{1}$ and $k_{2}$ are the slopes of fitted straight line shown in Figures 6 and 8, respectively. By substituting the corresponding slopes into Formula (7), the calculated strain 




FIgURE 7: Tested results from Step 2.

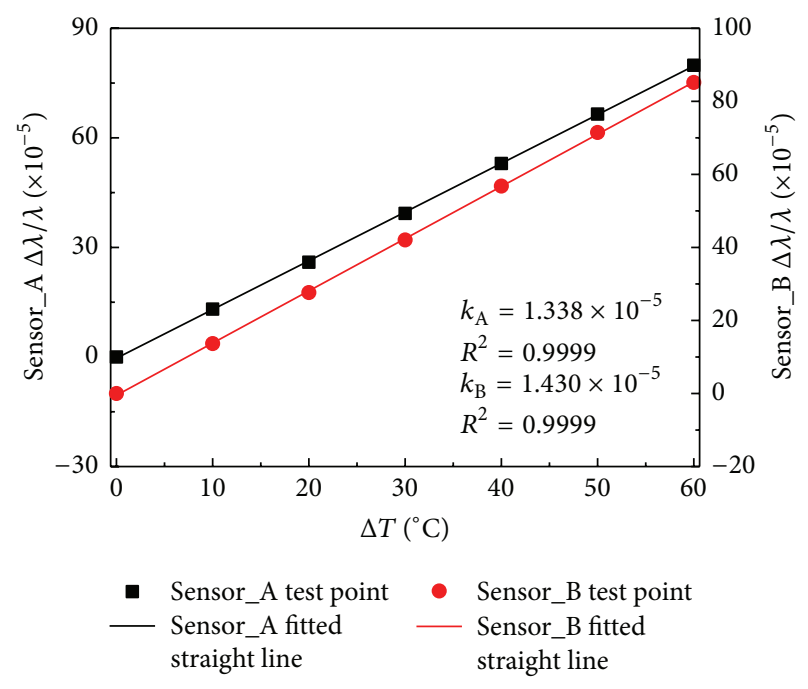

FIGURE 8: Fitting results.

sensitivity coefficients of the two sensors are 0.686 and 0.769 , respectively.

In Step 5, the displacement of the loading device has been set as unchangeable, and therefore along with the temperature rise of the TCB, the force load of the universal testing machine will also increase since the above-mentioned longitudinal temperature force in long seamless rails will be generated. Figure 9 shows the load variation of the universal testing machine during the test. For the tested wavelengths of the two FBGs, see Figure 10.

From the force load shown in Figure 9, it can be seen that the corresponding increased force loads of the test rail are different when the temperature rises by $10^{\circ} \mathrm{C}$ each time and the force load variation at each step is different from that calculated according to the material mechanics formula $\left[E \alpha_{s} A_{s} \Delta T\right]$ to a certain extent. Even though the displacement of the loading device does not change during the test, constraint of the test specimen in the test direction is incomplete since part of the loading device is in the TCB and the contact positions have inevitable gaps. Hence, in the test the rail is under both constrained and free states. The constrained and emitted temperature forces can be calculated according to the temperature inside the TCB and the force load variation.

Suppose that the force load variation of the universal testing machine is $\Delta F$; then the temperature variation corresponding to the constrained rail is $\Delta t_{1}=\Delta F / E \alpha_{s} A_{s}$; the temperature variation corresponding to the emitted longitudinal force of the rail is $\Delta t_{2}=\Delta T-\Delta t_{1}$; then the calculated relative shift of the central wavelength for the FBG, according to the sensing principles of Formulas (4) and (6), will be

$$
\frac{\Delta \lambda}{\lambda}=\left[K_{\varepsilon}\left(\alpha_{s}-\alpha\right)+K_{T}\right] \Delta t_{2}+K_{\varepsilon}\left(-\alpha \Delta t_{1}\right)+K_{T} \Delta t_{1} .
$$

Based on Figure 10, by taking the corresponding force load and sensor wavelength at $-30^{\circ} \mathrm{C}$ as the reference point, the relation between the relative shift of the central wavelength and the temperature variation can be obtained; see the black

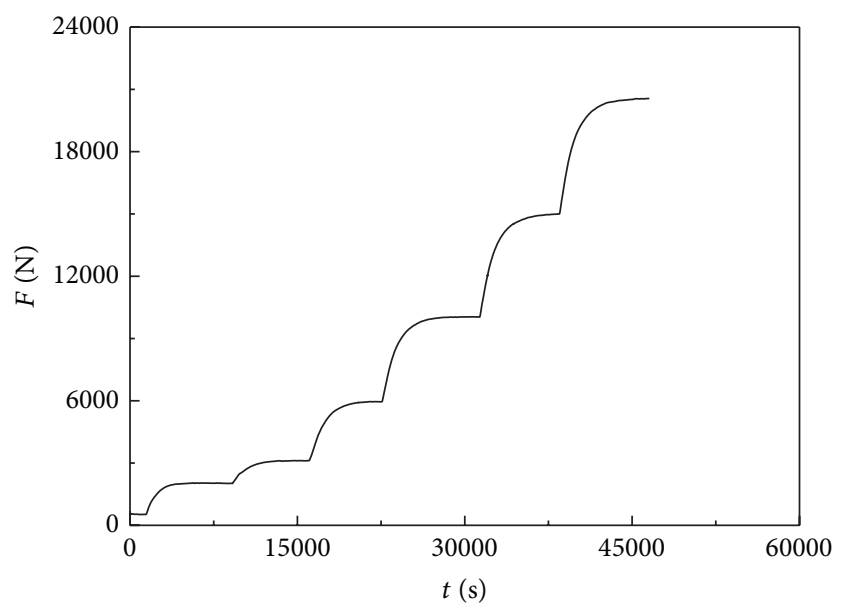

FIGURE 9: Force load curve.

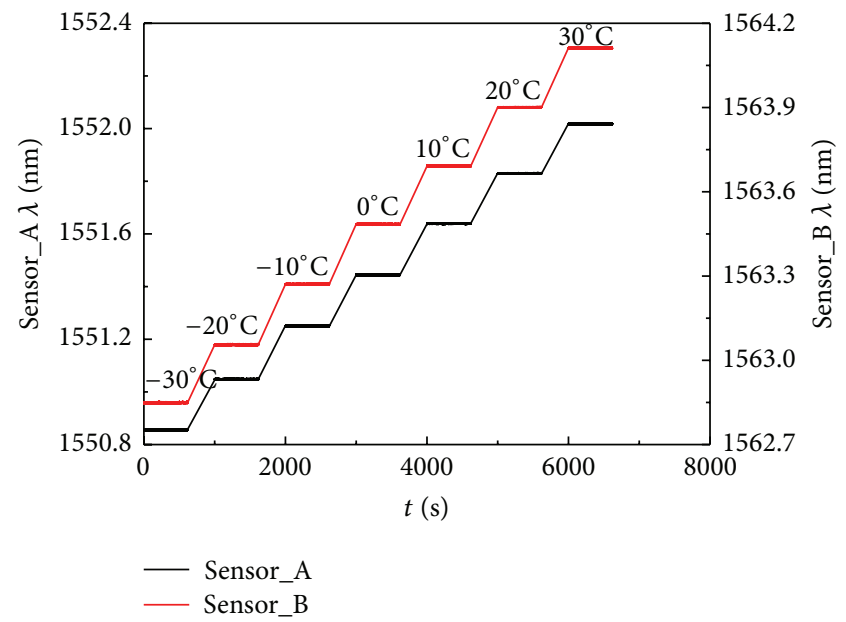

Figure 10: Tested results from Step 5. 
TABLE 2: Comparison between the slopes of fitted straight lines.

\begin{tabular}{|c|c|c|c|}
\hline \multicolumn{2}{|c|}{ Sensor_A } & \multicolumn{2}{|c|}{ Sensor_B } \\
\hline $\begin{array}{l}\text { Slope of line based on measured } \\
\text { value } /{ }^{\circ} \mathrm{C}^{-1}\end{array}$ & $\begin{array}{l}\text { Slope of line based on theoretical } \\
\text { value } /{ }^{\circ} \mathrm{C}^{-1}\end{array}$ & $\begin{array}{c}\text { Slope of line based on measured } \\
\text { value } /{ }^{\circ} \mathrm{C}^{-1}\end{array}$ & $\begin{array}{l}\text { Slope of line based on } \\
\text { theoretical value } /{ }^{\circ} \mathrm{C}^{-1}\end{array}$ \\
\hline $1.252 \times 10^{-5}$ & $1.233 \times 10^{-5}$ & $1.348 \times 10^{-5}$ & $1.317 \times 10^{-5}$ \\
\hline \multicolumn{2}{|c|}{ Relative error of two slopes } & \multicolumn{2}{|c|}{ Relative error of two slopes } \\
\hline \multicolumn{2}{|c|}{$1.5 \%$} & \multicolumn{2}{|l|}{$2.3 \%$} \\
\hline
\end{tabular}

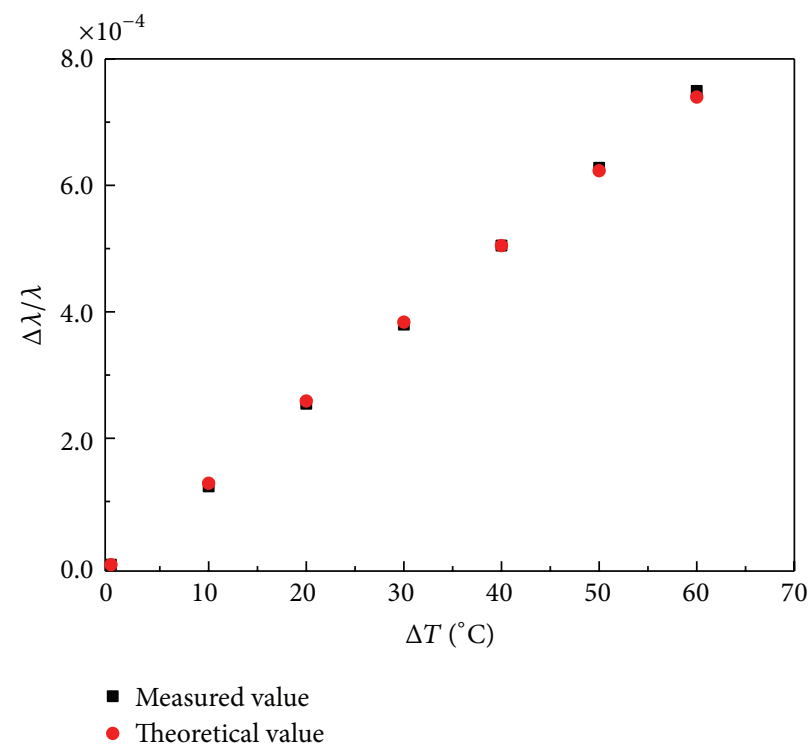

(a) Sensor_A

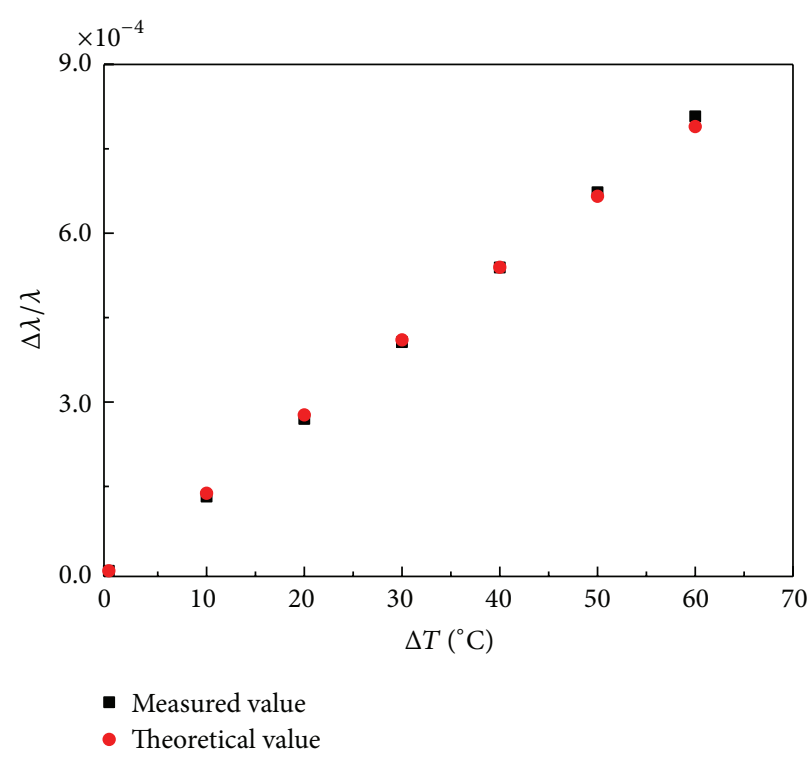

(b) Sensor_B

FIGURE 11: Comparison between measured and theoretical values.

points shown in Figure 11. The theoretical results can be calculated by substituting the load shown in Figure 9 as well as the sensing strain and temperature sensitivity coefficients into the sensing principle Formula (8); see the red points shown in Figure 11. Figure 11(a) shows the comparative results of sensor_A. Figure 11(b) shows the comparative results of sensor_B.

In view of the comparative results shown in Figure 11, as a whole, the measured and theoretical values of the two sensors are almost the same. For sensor_A, the maximum relative error of all points is $1.6 \%$, while for sensor_B, the relative error is a little bit higher at $3.2 \%$. Some of these errors are caused by inaccurately determined parameter values. Table 2 shows the comparison between the slopes of fitted straight lines based on the measured and theoretical values shown in Figure 11.

It can be seen from the comparative results shown in Table 2 that the differences between the slopes of straight lines obtained through measured value and theoretical value corresponding to the two sensors are almost the same, too. For sensor_A the slope error is only $1.5 \%$, while for sensor_B, the slope error is a little bit higher at $2.3 \%$, which also indicates clearly that both the measured values and theoretical values match ideally within the whole test temperature range.

Generally, the results obtained from the above test show the obvious effect of the specimen tested under different constraint states on the FBG sensing principle and prove the correctness of the FBG sensing principle when the specimen is tested under constraint. Therefore, the longitudinal temperature force of long seamless rails can be tested effectively based on the FBG sensing principle obtained when the specimen is tested under different constraint states.

\section{On-Site Applications}

4.1. Long Seamless Rail Testing Plan and Sensor Output. Based on the method for testing the longitudinal force of long seamless rails with resistance strain gauges [13], the longitudinal force can be obtained through testing the longitudinal and vertical sensor outputs of the corresponding rail web at the neutral axis of a piece of rail. This testing method can be adopted to determine the relative positional relationship between the FBG sensors and rail; see Figure 12.

The relative variation of the central wavelength corresponding to sensors in two directions can be calculated based on the FBG sensing principle Formulas (4) and (6) obtained under different constraint conditions:

$$
\begin{aligned}
& \frac{\Delta \lambda_{1}}{\lambda_{1}}=K_{\varepsilon 1}\left[\mu \alpha_{s} \Delta t+\left(\alpha_{s}-\alpha\right) \Delta t\right]+K_{T 1} \Delta t, \\
& \frac{\Delta \lambda_{2}}{\lambda_{2}}=-K_{\varepsilon 2} \alpha \Delta t+K_{T 2} \Delta t .
\end{aligned}
$$




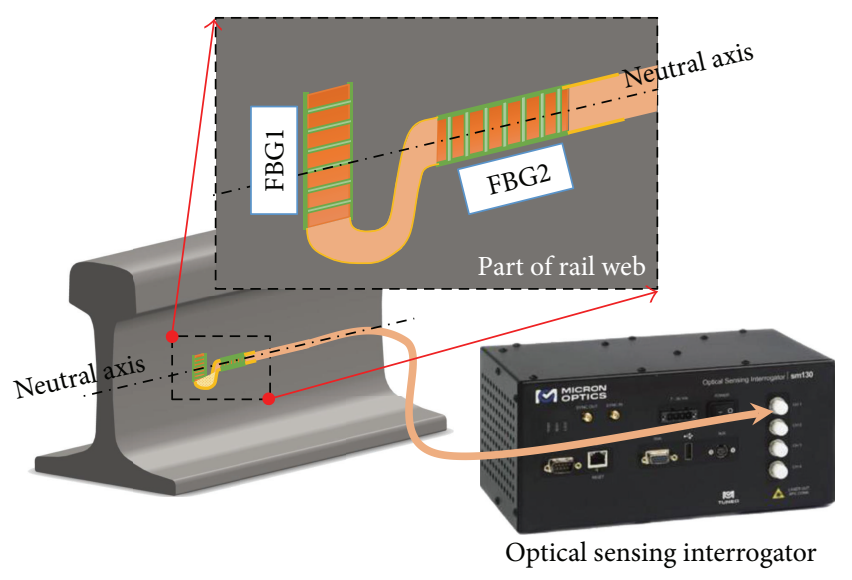

FIGURE 12: Relative positional relationship between sensors and rail.

Suppose $K_{\varepsilon 2}=n_{\varepsilon} K_{\varepsilon 1}$ and $K_{T 2}=n_{T} K_{T 1}$; then

$$
\begin{aligned}
\frac{\left(\Delta \lambda_{1} / \lambda_{1}-\Delta \lambda_{2} / \lambda_{2}\right)}{K_{\varepsilon 1}(\mu+1)}= & \alpha_{s} \Delta t+\frac{\left(n_{\varepsilon}-1\right) \alpha \Delta t}{\mu+1} \\
& +\frac{K_{T 1} \Delta t\left(1-n_{T}\right)}{K_{\varepsilon 1}(\mu+1)}
\end{aligned}
$$

where $\alpha_{s} \Delta t$ refers to the temperature strain that is not emitted due to the constraint of the long seamless rail. The product of the temperature strain, Young's modulus, and sectional area of rail is the longitudinal temperature force of the long seamless rail [5]. $\left(n_{\varepsilon}-1\right) \alpha \Delta t /(\mu+1)+K_{T 1} \Delta t\left(1-n_{T}\right) /(\mu+$ 1) refers to the error caused by the unequal strain and temperature sensitivity coefficients of the two sensors. The difference between temperature sensitivity coefficients of bare grating sensors is low (the conclusion also obtained according to the above test), and therefore the effect of the unequal temperature sensitivity coefficients of the two sensors can be ignored. The error is mainly caused by the unequal strain sensitivity coefficients of the two sensors; the relative error between measured value and theoretical value is

$$
\left|\frac{\left(n_{\varepsilon}-1\right) \alpha}{(\mu+1) \alpha_{s}}\right|=0.0358\left|n_{\varepsilon}-1\right| \text {. }
$$

It is obvious that the lower the difference between the strain sensitivity coefficients of sensors in two directions is, the lower the relative error will become. If the two sensors of the above test are used, the corresponding maximum relative error is only $0.43 \%$, which can satisfy the requirements of on-site testing. Considering the inequality property, a sensor with a higher strain sensitivity coefficient, if possible, should be used for testing the vertical strain at the position shown at FBG1 in Figure 12, in order to further reduce the relative error. Under the above conditions, the change of the longitudinal temperature force of long rails measured with FBG sensor is obtained from

$$
\Delta F=E A \alpha_{s} \Delta t=E A \frac{\left(\Delta \lambda_{1} / \lambda_{1}-\Delta \lambda_{2} / \lambda_{2}\right)}{K_{\varepsilon 1}(\mu+1)},
$$

where $A$ refers to the sectional area of rails used on-site and the value is $77.45 \times 10^{-4} \mathrm{~m}^{2}$.

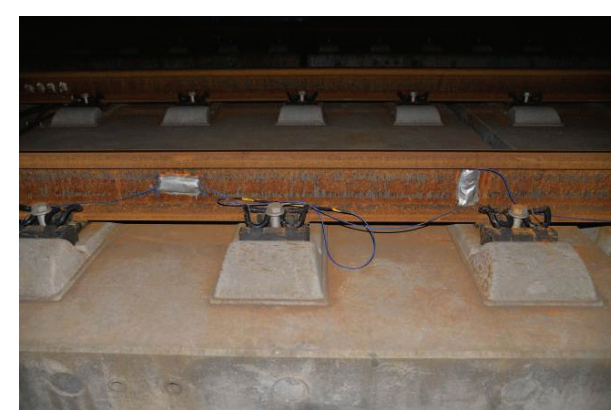

FIGURE 13: On-site sensor installation and protective encapsulation.

4.2. On-Site Test Process and Results. A segment of CWR of one high-speed railway line in China was selected as the test point area, which is situated in a subgrade section and is far away from special structural parts such as bridge abutments and turnouts. It was ensured that this test point was sure in the fixed area of CWR. The sensors were set according to Figure 12. The selected sensors were the same as those used for the indoor test. The one with a higher strain sensitivity coefficient was installed in the vertical direction, and the other was installed in the longitudinal direction. Protective encapsulation was arranged in order to prevent the sensors from being affected by the surrounding environment of the railroad; see Figure 13.

In order to verify the correctness of the longitudinal force in the long seamless rail tested by the FBG sensors, a rail temperature sensor was set at the test point; thus the rail temperature variation could be tested and the longitudinal temperature force of the long seamless rail could be calculated. Figure 14 shows the rail temperature variation curve as well as the longitudinal temperature force of the rail calculated based on the corresponding theoretical formula during the test, where the longitudinal force of the rail is negative under pressure and positive under tension when the test is started.

The site test lasted about 16 hours, the maximum rail temperature variation during the test was $6.3^{\circ} \mathrm{C}$, and the corresponding longitudinal force variation of the rail was $120.9 \mathrm{kN}$. Figure 15 shows the relative variation difference curve of the central wavelengths corresponding to the vertical and longitudinal sensors of the test point. The site test also had many clutter signals due to the accuracy of the interrogator. The true values can be effectively maintained and the effect of the clutter, namely, the red curve shown in the figure, can be removed through the S-G filtering method.

Figure 16 shows the comparison between the longitudinal temperature force in the long seamless rail tested by the FBG sensors and the calculated results.

From the comparison shown in Figure 16, though the longitudinal temperature of the rail tested under different constraint states matches with the calculated results, a certain difference still exists, which is caused by several factors. First, the surface temperature of the rail is uneven. Errors will exist if the temperature of one point is adopted instead of that of the whole section, and therefore there is an error between 


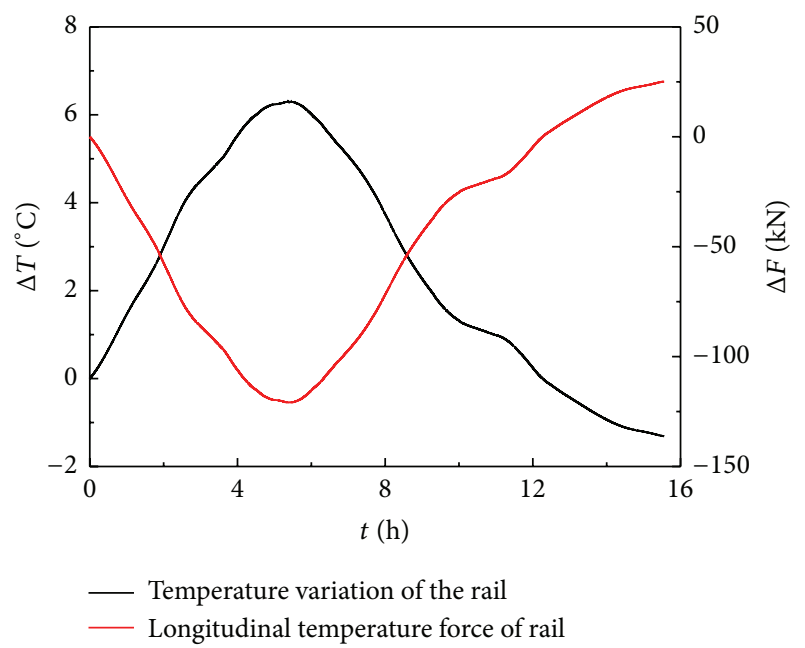

Figure 14: Temperature and longitudinal force variation curves of rail.

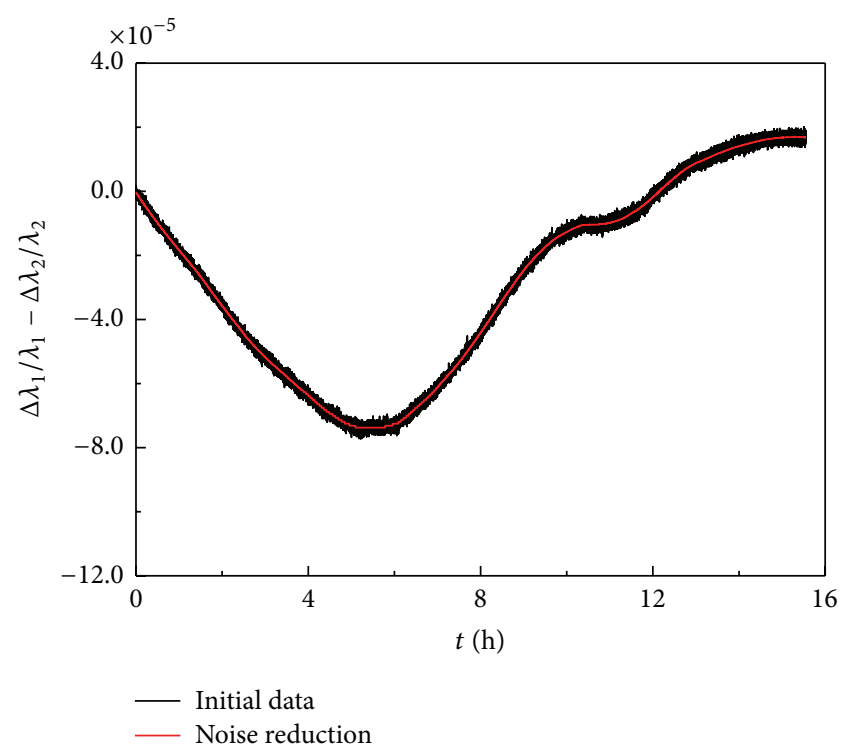

FIGURE 15: Relative variation difference curve of the central wavelengths.

the longitudinal temperature force in the long seamless rail calculated based on the rail temperature variation directly and the true value. Second, the testing accuracy of the interrogator, to some extent, can not only affect the strain sensitivity coefficient of sensors but also cause errors in the site test, making the longitudinal temperature force in the rail tested with FBG sensors different from the true values. Third, the strain and temperature sensitivity coefficients of the two sensors are different; however errors caused by them are low. Fourth, some errors might be caused during data filtering. Generally, the maximum difference value between them is $6.1 \mathrm{kN}$, the corresponding rail temperature variation is $0.3^{\circ} \mathrm{C}$, the accumulated error during the site measurement is controllable within $5 \%$, and therefore the engineering applications requirements can be satisfied.

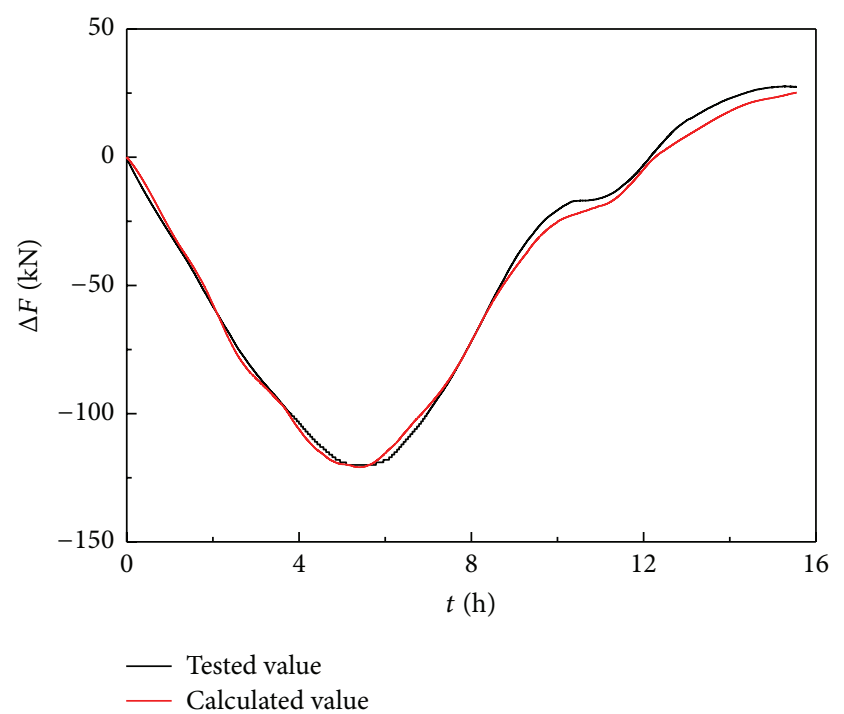

FIGURE 16: Comparison between the tested and calculated values.

\section{Conclusions}

In this paper, considering the cross sensitivity of fiber gratings, FBG sensing principles are deduced with reference to the specimen tested under different constraint conditions, and the indoor test verification is performed. Based on which, a solution for testing the longitudinal temperature force of long seamless rails is designed. The on-site application is a success. According to the above description, it can be concluded that

(1) when the test specimen is constrained and the temperature changes, the relative variation of the corresponding central wavelength will be independent of the thermal expansion coefficient of the test specimen and the temperature strain the FBG cannot emit will be reflected in the sensing principle in the form of compressive strain due to the constraint of the test specimen;

(2) the temperature and strain sensitivity coefficients of the FBG can be calculated based on the test. They are related to the selected base temperature; however their effect within $-30^{\circ} \mathrm{C} \sim 30^{\circ} \mathrm{C}$ is not higher than $0.05 \%$;

(3) the maximum relative error of single point between the tested and theoretical results of test specimen under constrained condition is $3.2 \%$, and the maximum relative error of slopes of fitted straight lines based on the tested and theoretical results within the entire test temperature range is $2.3 \%$, verifying the deduced FBG sensing principle with regard to specimens tested under constrained condition;

(4) the maximum error between the on-site tested and calculated longitudinal temperature force results of long seamless rails is only $6.1 \mathrm{kN}$, the corresponding rail temperature variation is $0.3^{\circ} \mathrm{C}$, and the accumulated error is controllable within 5\%. Therefore, 
the requirements of engineering applications can be satisfied.

\section{Competing Interests}

The authors declare that there are no competing interests regarding the publication of this paper.

\section{Acknowledgments}

The authors thank the fund support by the National Natural Science Foundation of China (no. 51425804, no. U1234201, no. 1334203, and no. 61475128), the International Science and Technology Cooperation Program of China (2014DFA11170), the Fundamental Research Fund for the Central Universities (2682014RC22), and the Doctorial Innovation Fund of Southwest Jiaotong University.

\section{References}

[1] A. L. Tzepushelov and L. F. Troyitzky, "Design, laying, maintenance and repair of continuous welded rails on the ussr railways," Rail International, vol. 9, pp. 589-614, 1974.

[2] A. Strauss, S. Karimi, F. Kopf, C. Capraru, and K. Bergmeister, "Monitoring-based performance assessment of rail-bridge interaction based on structural reliability," Structural Concrete, vol. 16, no. 3, pp. 342-355, 2015.

[3] N.-H. Lim, N.-H. Park, and Y.-J. Kang, "Stability of continuous welded rail track," Computers and Structures, vol. 81, no. 22-23, pp. 2219-2236, 2003.

[4] R. Chen, P. Wang, and X.-K. Wei, “Track-bridge longitudinal interaction of continuous welded rails on arch bridge," Mathematical Problems in Engineering, vol. 2013, Article ID 494137, 8 pages, 2013.

[5] C. Esveld, Modern Railway Track, MRT Production, 1989.

[6] X. Zhu, F. L. D. Scalea, and M. Fateh, "On the study of the insitu thermal stress measurement using a Hole-Drilling method," in Proceedings of the 11th International Workshop on Advanced Smart Materials and Smart Structures Technology, UrbanaChampaign, Ill, USA, August 2015.

[7] K. Towpik, "Variability of stress and longitudinal force distributed in continuous welded rail tracks," Archives of Civil Engineering, vol. 52, no. 4, pp. 701-709, 2006.

[8] M. Hirao, H. Ogi, and H. Fukuoka, "Advanced ultrasonic method for measuring rail axial stresses with electromagnetic acoustic transducer," Research in Nondestructive Evaluation, vol. 5, no. 3, pp. 211-223, 1994.

[9] Y. Sato, "Study on measurement of rail longitudinal force on slab track by rail lifting," in Proceedings of the 8th International Conference on Computers in Railways, pp. 571-580, Lemnos, Greece, 2002.

[10] A. Aikawa, H. Sakai, and K. Abe, "Numerical and experimental study on measuring method of rail axial stress of continuous welded rails based on use of resonant frequency," Quarterly Report of RTRI, vol. 54, no. 2, pp. 118-125, 2013.

[11] Y. Luo, "A model for predicting the effect of temperature force of continuous welded rail track," Proceedings of the Institution of Mechanical Engineers, Part F: Journal of Rail and Rapid Transit, vol. 213, no. 2, pp. 117-124, 1999.
[12] H. D. Harrison, T. O. McCanney, and L. L. Doll, "Wayside system for measuring rail longitudinal force due to thermal expansion of continuous welded rail," in Nondestructive Evaluation of Aging Railroads, vol. 2458 of Proceedings of SPIE, pp. 225-231, Oakland, Calif, USA, June 1995.

[13] B. Wang, K. Z. Xie, J. L. Xiao, and P. Wang, “Test principle and test scheme of longitudinal force in continuous welded rail using resistance strain gauge," Journal of Southwest Jiaotong University, vol. 51, no. 1, pp. 43-49, 2016.

[14] W. W. Morey, G. Meltz, and W. H. Glenn, "Fiber optic Bragg grating sensors," in Fiber Optic and Laser Sensors VII, vol. 1169 of Proceedings of SPIE, pp. 98-107, Boston, Mass, USA, September 1989.

[15] W. Ecke, L. Latka, R. Willsch, A. Reutlinger, and R. Graue, "Optical fibre grating strain sensor network for X-38 spacecraft health monitoring," in 14th International Conference on Optical Fibre Sensors, vol. 4185 of Proceedings of SPIE, pp. 888-891, Venice, Italy, 2000.

[16] M. N. Trutzel, K. Wauer, D. Betz et al., "Smart sensing of aviation structures with fiber optic Bragg grating sensors," in Smart Structures and Materials 2000: Sensory Phenomena and Measurement Instrumentation for Smart Structures and Materials, vol. 3986 of Proceedings of SPIE, pp. 134-143, Newport Beach, Calif, USA, June 2000.

[17] T. H. T. Chan, L. Yu, H. Y. Tam et al., "Fiber Bragg grating sensors for structural health monitoring of Tsing Ma bridge: background and experimental observation," Engineering Structures, vol. 28, no. 5, pp. 648-659, 2006.

[18] B. N. Shivananju, M. Kiran, S. P. Nithin, M. J. Vidya, G. M. Hegde, and S. Asokan, "Real time monitoring of petroleum leakage detection using etched fiber Bragg grating," in International Conference on Optics in Precision Engineering and Nanotechnology (icOPEN '13), Proceedings of SPIE, Singapore, April 2013.

[19] Y.-J. Rao, D. J. Webb, D. A. Jackson, L. Zhang, and I. Bennion, "In-fiber bragg-grating temperature sensor system for medical applications," Journal of Lightwave Technology, vol. 15, no. 5, pp. 779-784, 1997.

[20] Z.-F. Wang, J. Wang, Q.-M. Sui et al., "Development and application of smart geogrid embedded with fiber Bragg grating sensors," Journal of Sensors, vol. 2015, Article ID 108209, 10 pages, 2015.

[21] M. L. Filograno, P. C. Guillén, A. Rodríguez-Barrios et al., "Realtime monitoring of railway traffic using fiber Bragg grating sensors," IEEE Sensors Journal, vol. 12, no. 1, pp. 85-92, 2012.

[22] C.-L. Wei, C.-C. Lai, S.-Y. Liu et al., "A fiber Bragg grating sensor system for train axle counting," IEEE Sensors Journal, vol. 10, no. 12, pp. 1905-1912, 2010.

[23] L. S. Yan, Z. T. Zhang, P. Wang et al., "Fiber sensors for strain measurements and axle counting in high-speed railway applications," IEEE Sensors Journal, vol. 11, no. 7, pp. 1587-1594, 2011.

[24] C. C. Lai, J. C. P. Kam, D. C. C. Leung et al., "Development of a fiber-optic sensing system for train vibration and train weight measurements in Hong Kong," Journal of Sensors, vol. 2012, Article ID 365165, 7 pages, 2012.

[25] N. Roveri, A. Carcaterra, and A. Sestieri, "Real-time monitoring of railway infrastructures using fibre Bragg grating sensors," Mechanical Systems and Signal Processing, vol. 60, pp. 14-28, 2015.

[26] S. J. Buggy, S. W. James, S. Staines, R. Carroll, P. Kitson, and D. Farrington, "Railway track component condition monitoring 
using optical fibre Bragg grating sensors," Measurement Science and Technology, vol. 27, no. 5, Article ID 055201, 2016.

[27] K. Y. Lee, K. K. Lee, and S. L. Ho, "Exploration of using FBG sensor for derailment detector," WSEAS Transactions Topics Systems, no. 3, pp. 2433-2439, 2004.

[28] K. Schröder, W. Ecke, M. Kautz, S. Willett, M. Jenzer, and T. Bosselmann, "An approach to continuous on-site monitoring of contact forces in current collectors by a fiber optic sensing system," Optics and Lasers in Engineering, vol. 51, no. 2, pp. 172179, 2013.

[29] K. Schröder, W. Ecke, M. Kautz et al., "Smart current collectorfibre optic hit detection system for improved security on railway tracks," Measurement Science and Technology, vol. 24, no. 11, Article ID 115104, 2013.

[30] A. Catalano, F. A. Bruno, M. Pisco, A. Cutolo, and A. Cusano, "An intrusion detection system for the protection of railway assets using fiber bragg grating sensors," Sensors, vol. 14, no. 10, pp. 18268-18285, 2014.

[31] X. Chapeleau, T. Sedran, L.-M. Cottineau et al., "Study of ballastless track structure monitoring by distributed optical fiber sensors on a real-scale mockup in laboratory," Engineering Structures, vol. 56, pp. 1751-1757, 2013.

[32] H.-J. Yoon, K.-Y. Song, J.-S. Kim, and D.-S. Kim, "Longitudinal strain monitoring of rail using a distributed fiber sensor based on Brillouin optical correlation domain analysis," NDT and E International, vol. 44, no. 7, pp. 637-644, 2011.

[33] C.-Y. Wang, H.-C. Tsai, C.-S. Chen, and H.-L. Wang, "Railway track performance monitoring and safety warning system," Journal of Performance of Constructed Facilities, vol. 25, no. 6, pp. 577-586, 2011.

[34] C. X. Wu and F. Wu, Sensing Principle and Application of Fiber Optical Grating, National Defence Industry Press, 2011.

[35] P. Childs, A. C. L. Wong, N. Gowripalan, and G. D. Peng, "Measurement of the coefficient of thermal expansion of ultrahigh strength cementitious composites using fibre optic sensors," Cement and Concrete Research, vol. 37, no. 5, pp. 789-795, 2007.

[36] G. F. Fernando, D. J. Webb, and P. Ferdinand, "Optical-fiber sensors," MRS Bulletin, vol. 27, no. 5, pp. 359-361, 2002.

[37] Y. G. Zhan, H. W. Cai, J. X. Geng, R. H. Qu, S. Q. Xiang, and X. Z. Wang, "Study on aluminum groove encapsulating technique and sensing characteristics of FBG sensor," Acta Photonica Sinica, vol. 33, no. 8, pp. 952-955, 2004. 


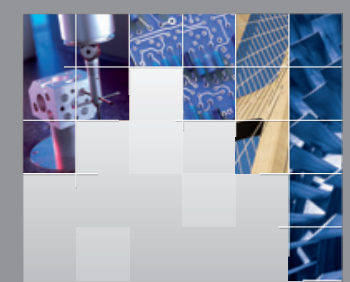

\section{Enfincering}
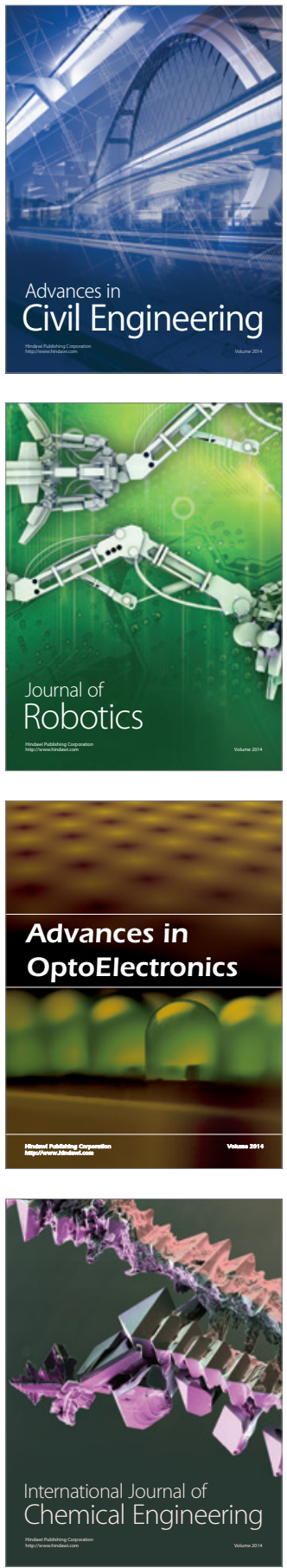



The Scientific World Journal

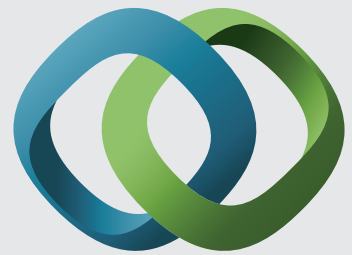

\section{Hindawi}

Submit your manuscripts at

http://www.hindawi.com
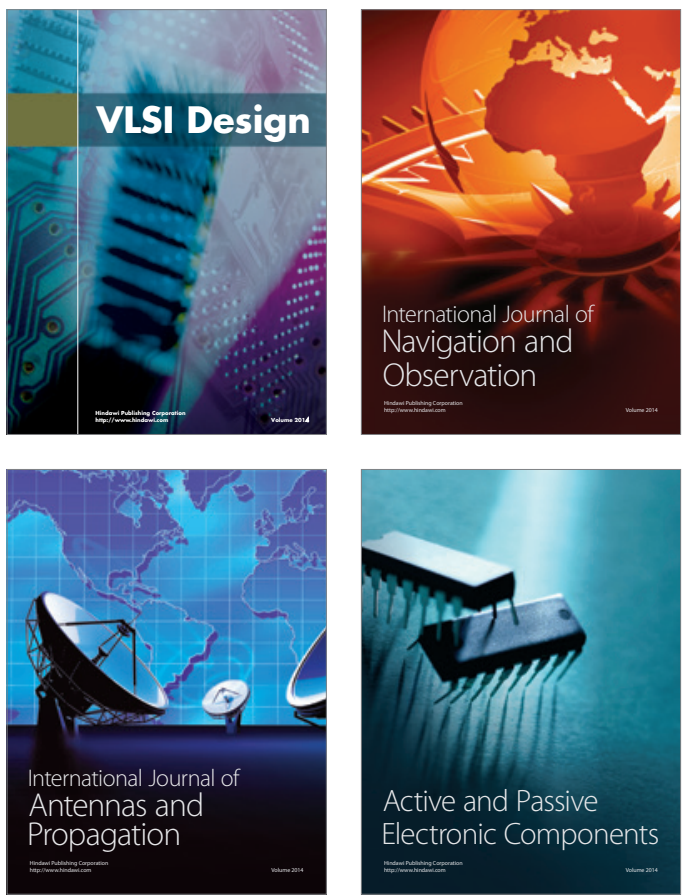


International Journal of

Distributed

Sensor Networks

Journal of

Control Science

and Engineering
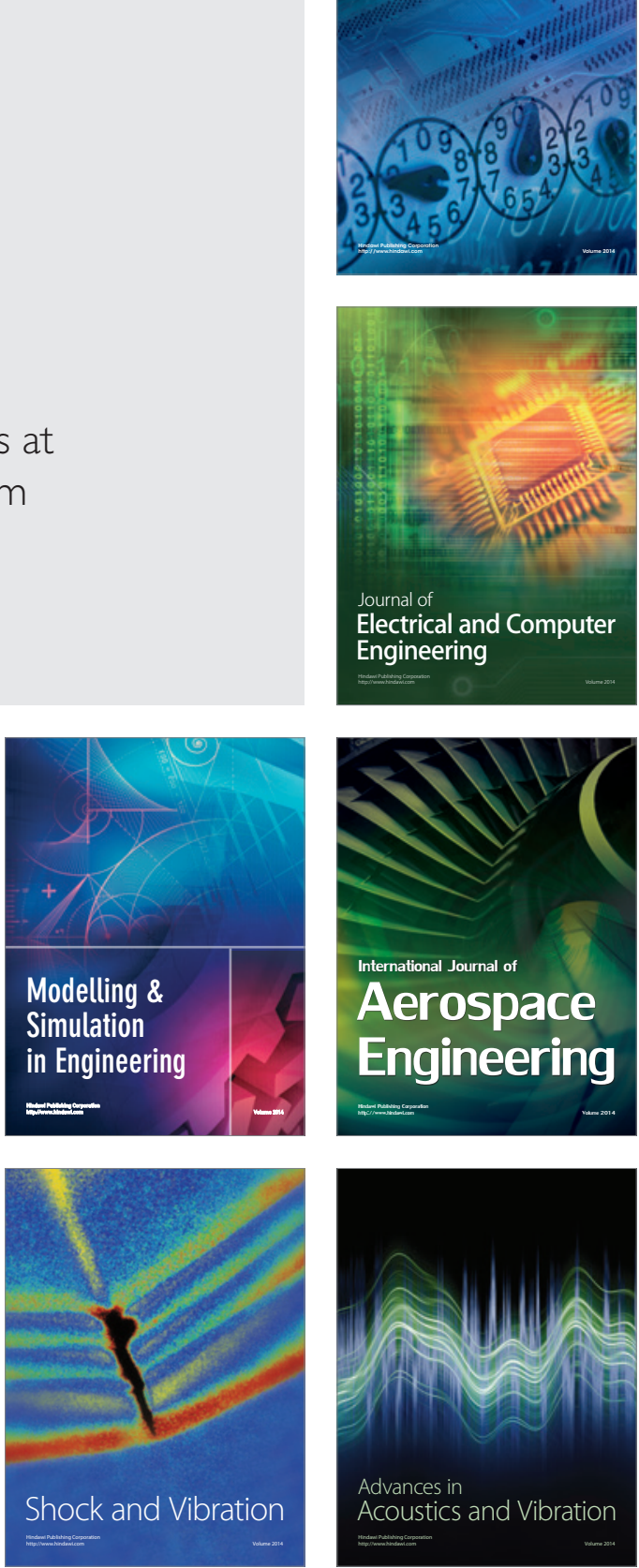